\title{
Integrin $\alpha 5 \beta 1$ Mediated Cellular Reorganization in Human Mesenchymal Stem Cells During Neuronal Differentiation
}

\author{
NİHAL KARAKAŞ ${ }^{1,2}$ and ÜLKAN KILIÇ ${ }^{3}$ \\ ${ }^{1}$ Department of Medical Biology, School of Medicine, Istanbul Medipol University, Istanbul, Turkey; \\ ${ }^{2}$ Regenerative and Restorative Medicine Research Center (REMER), \\ Institute for Health Sciences and Technologies (SABITA), Istanbul Medipol University, Istanbul, Turkey; \\ ${ }^{3}$ Department of Medical Biology, Hamidiye School of Medicine, University of Health Sciences Turkey, Istanbul, Turkey
}

\begin{abstract}
Background/Aim: Mesenchymal stem cells (MSCs) have been widely used for yielding neurons in culture to study nervous system pathologies and develop regenerative approaches. In this study, cellular rearrangements of human MSCs related to the expression of the fibronectin common receptor integrin $\alpha 5 \beta 1$ and its cell surface localization during neuronal differentiation, were examined. Materials and Methods: Proliferation kinetics of neuronal induced hMSCs (hMd-Neurons) were quantified by $B r d U$ assay, and hMd-Neurons were immunostained for neuronal marker expression. Additionally, cDNA and protein samples were collected at different time points for integrin $\alpha 5 \beta 1$ expression analysis. Results: Endogenous integrin $\alpha 5 \beta 1$ expression was significantly upregulated by day 6 and maintained until day 12. Cell surface localization of $\alpha 5 \beta 1$ integrin was increased by day 6; the integrin was internalized into the cytosol by day 12. Conclusion: Integrin dynamics around day 6 of differentiation might be involved in neuronal differentiation and maturation or specification of hMd-Neurons.
\end{abstract}

Mesenchymal stem cells (MSCs) are one of the most promising stem cell type due to their availability and relatively simple requirements for in vitro expansion and genetic manipulation $(1,2)$. Multipotential differentiation of MSCs has been detailed by Friedenstein and coworkers in the mid-1970's and modified by other groups in the 1990's

This article is freely accessible online.

Correspondence to: Nihal Karakaş, Istanbul Medipol Universitesi, Tıp Fakultesi, Tibbi Biyoloji, Kavacik Mah. Ekinciler Cad. No.19 Kavacik Kavsagi-Beykoz 34810 Istanbul, Turkey. Tel: +90 5356111313,e-mail: nkarakas@medipol.edu.tr

Key Words: Mesenchymal stem cells, neuronal differentiation, integrin, integrin $\alpha 5 \beta 1$.
(3-6). Due to their general multipotential differentiation capacity and relative ease of isolation from numerous tissues, MSCs have been considered in tissue engineering and therapeutic applications $(7,8)$. The plasticity and self renewal ability of MSCs offer a huge potential for clinical tissue regeneration $(9,10)$. MSCs have been isolated from a number of tissues, including foetal blood, cord blood, bone-marrow, and amniotic fluid $(11,12)$. One of the most studied and accessible source of MSCs is the bone marrow (BM). Human bone marrow derived MSCs can be prolonged in an undifferentiated state in vitro, but have the ability to generate a functional stroma, to support hematopoiesis, or to differentiate along osteogenic, chondrogenic, and adipogenic lineages under certain conditions (13). Additionally, MSCs can also transdifferentiate into neurons. This ability of MSCs facilitates their use in neural tissue devolopment and repair.

Neural differentiation of MSCs in vitro was reported from two simultaneous studies by Sanchez-Ramos et al. and Woodbury et al. in $2000(14,15)$. These two studies were the pioneers for establishing MSC-derived neuronal cells. Afterwards, a number of protocols were reported for developing an optimized method for neuronal induction of MSCs (16-25).

Human MSCs express a large number of different cell surface proteins, including various integrins, growth factor receptors (bFGFR, PDGFR, EGFR, TGF $\beta$ IR/IIR), chemokine receptors (interleukins, $\mathrm{CC}$ and $\mathrm{CXC}$ receptors) and cell adhesion molecules (VCAM-1, ICAM-1/', ALCAM1, L-selectin, CD105, CD44). Moreover, hMSCs produce a vast array of matrix molecules including fibronectin, collogens, laminin, and proteoglycans (26).

As a first significant finding, in 2001, Gronthos and his colleagues examined the mechanisms mediating the growth of hMSCs on different extracellular matrix (ECM) components. In summary, they found that hMSCs show a higher colony-forming efficiency when seeded onto collagen type IV, fibronectin, vitronectin, and laminin coated surfaces 
in comparison with collagen type I and III (27). This may be caused by their functional origin in the BM, stage of commitment, and unique integrin expression. Moreover, this study revealed that $\beta 1$ integrin seems to have a regulatory function in the in vitro differentiation of hMSCs into osteoblasts. Furthermore, plenty of data have been provided by studies on the involvement of integrins during in vitro osteogenic, chondrogenic, and adipogenic differentiation of hMSCs $(13,28,29)$. Consequently, it is a promising area of research to study spesific patterns of integrin expression and utilizations in hMSCs. Understanding the underlying mechanisms of hMSC differentiation in relation tointegrin dynamics may aid in the development of novel therapeutic and tissue engineering approaches.

Integrin $\alpha 5 \beta 1$ is a transmembrane receptor that binds to fibronectin (Fn) through its extracellular domain and its cytoplasmic tail interacts with intracellular actin filaments (30-33). Among other members of the integrin family receptors, $\alpha 5 \beta 1$ is a fibronectin specific integrin that can be found in different adhesion structures and has been implicated in the control of differentiation of various cell types, such as precursor osteogenic cells (34-37). Integrin $\alpha 5 \beta 1$ is also known as the "fibronectin common receptor" due to its specific binding property on this core ECM protein. Functionally, $\alpha 5 \beta 1$ interaction requires both the traditional integrin-binding sequence (RGD) as well as the synergy sequence (PHSRN), whereas most other RGD dependent integrins do not require PHSRN (38). Besides, this receptor-ligand pair (integrin $\alpha 5 \beta 1-\mathrm{Fn}$ ) is functionally very important because it mediates fibronectin fibril formation and governs ECM assembly, which is vital to cell function in vivo. The interaction between $\alpha 5 \beta 1$ and $F n$ is fundamental for vertebrate development, since lack of $\alpha 5 \beta 1$ or Fn results in early embryonic lethality (39-41). Since Fn is believed to be the most common fibronectin receptor and a significant component of the framework of hMSCs, integrin $\alpha 5 \beta 1$ has been used to investigate hMSC-integrin engagement. Martino et al. demonstrated that $\alpha 5 \beta 1$ has an important role in the control of MSC osteogenic differentiation (42).

Considering previously suggested cellular dynamics regulated by integrin $\alpha 5 \beta 1$, in this study, involvement of integrin $\alpha 5 \beta 1$ in neuronal differentiation of hMSCs was examined based on a differentiation protocol we previously reported (43). The results showed that cytokine based induction of hMSCs into hMd-Neurons requires integrin $\alpha 5 \beta 1$ surface localization at specific time points (around day 5), while translocation into the cytosol was observed during further maturation. Considering the integrin $\alpha 5 \beta 1$ expression profile of $\mathrm{hMd}-\mathrm{Neurons}$, these findings suggest that modification of the hMSC neuronal induction environment may contribute to neuronal differentiation and maturation or specification of hMd-Neurons.

\section{Materials and Methods}

Culture of hMSCs. To analyse neuronal differentiation of hMSCs, a commercial hMSC cell line (UE7T-13 cells, no RBRC-RCB2161; RIKEN, Wako, Japan) was used. hMSCs were maintained in DMEM (GIBCO, New York, NY, USA) containing 10\% FBS $+1 \%$ Penicillin/Streptomycin and cells were incubated at $37^{\circ} \mathrm{C}$, in an atmosphere containing $5 \% \mathrm{CO}_{2}$. Cultured hMSCs were subcultured at $80-90 \%$ confluency.

Flow cytometry analysis. To confirm that isolated cells from human $\mathrm{BM}$ were hMSCs at passage 3 , cells were analyzed using immunotyping. For this, flow cytometry was performed using a FACS system (BD Influx Cell Sorter with Bioprotect IV Safety Cabinet). The data were analysed with FlowJo (Tree Star) software (FlowJo LLC, Ashland, OR, USA) and the forward and side scatter profile was used to gate out debris and dead cells. Immunophenotyping of hMSC was performed with antibodies against the following antigens: CD44 (ab27285; Abcam, Cambridge, MA, USA), CD73 (ab157335; Abcam), CD90 (ab11155; Abcam), CD105 (ab53321; Abcam), CD34 (ab18227; Abcam), CD45 (ab134202; Abcam), and their isotype controls (IgG1 FITC, IgG2a PE, IgG1 PE) (Abcam).

Neuronal differentiation. hMSCs were seeded in culture dishes prior to neural induction. Cell frequency was set at 3,000 cells $/ \mathrm{cm}^{2}$. The culture was maintained in DMEM containing 10\% MSC-FBS and $1 \%$ Penicillin/Streptomycin; the cells were incubated at $37^{\circ} \mathrm{C}$ in $5 \%$ $\mathrm{CO}_{2}$ for $24 \mathrm{~h}$. Previously defined neuronal induction media, composed of $20 \mathrm{ng} / \mathrm{ml} \mathrm{hEGF}$ (human epidermal growth factor), 40 $\mathrm{ng} / \mathrm{ml}$ bFGF (basic fibroblast growth factor), $10 \mathrm{ng} / \mathrm{ml}$ FGF-8 (fibroblast growth factor-8), $10 \mathrm{ng} / \mathrm{ml}$ human BDNF (human brainderived neurotrophic factor), $40 \mathrm{ng} / \mathrm{ml} \mathrm{NGF,} 0.125 \mathrm{mM}$ dbcAMP (dibutyryl cyclic AMP), $0.5 \mathrm{mM}$ IBMX (3-isobutyl-1methylxanthine), $2 \mathrm{mM}$ L-Glutamine in Neurobasal medium, and B27 supplement in the absence of serum was used for neural differentiation (43). Then, cells were refreshed with neural induction media every $48 \mathrm{~h}$ for 12 days. Samples were collected for western blotting and RT-PCR.

Immunofluorescence staining. The medium was aspirated off and cells were permeablized with prewarmed TZN buffer $(10 \mathrm{mM} \mathrm{pH}$ 7.5 Tris- $\mathrm{HCl}, 0.5 \%$ Nondet $\mathrm{P} 40,0.2 \mathrm{mM} \mathrm{ZnCl}_{2}$ ) at RT for $15 \mathrm{~min}$ by mixing on a rocking shaker at very low speed (when staining membrane bounded integrins, TZN treatment was not applied). Cells were then fixed with $4 \%$ paraformaldehyde in phosphate buffer saline (PBS; Sigma, St. Louis, MO, USA) and incubated at RT for $15 \mathrm{~min}$. After washing with PBS, cells were blocked with a solution containing 1\% normal goat serum (Sigma), 3\% BSA (Sigma) $0.3 \%$ sodium azide (Sigma), and $0.1 \%$ Triton $\mathrm{X}$ in PBS (PBS-Tx) to prevent nonspesific binding.. After discarding the blocking solution, cells were treated with primary antibodies: Anti-Integrin $\alpha 5 \beta 1$ (Chemicon, Merck KGaA, Darmstadt, Germany; $20 \mu \mathrm{g} / \mathrm{ml}$ ), Anti-Actin (Santa Cruz Biotechnology, Inc., Dallas, TX, USA; $10 \mu \mathrm{g} / \mathrm{ml}$ ), Anti-Neurofilament (NF-H) (Chemicon; $10 \mu \mathrm{g} / \mathrm{ml}$ ), Anti-NSE, (Chemicon, $10 \mu \mathrm{g} / \mathrm{ml}$ ), AntiNeuN (Chemicon, $50 \mu \mathrm{g} / \mathrm{ml}$ ), in PBS containing 3\% BSA (Sigma), $0.3 \%$ sodium azide (Sigma), 1\% Tween-20 and 3\% normal human serum (NHS, Biochrom, Ltd., Cambridge, UK) and incubated at $4^{\circ} \mathrm{C}$ overnight. Normal human serum was applied 
onto the negative control wells instead of primary antibodies and after antibody exposure both wells were washed with PBS for three times. Cells were then incubated at RT for $3 \mathrm{~h}$ with 1:200 diluted goat-anti Mouse (GAM) IgG Alexa Fluor 488 (Abcam; ab150113), 1:200 diluted goat anti rabbit (GAR) IgG Alexa Fluor 488 (Abcam; ab150077), 1:200 diluted donkey anti-goat (DAG) IgG Alexa Fluor 568 (Abcam; ab175474), 1:500 diluted goat antirabbit (GAR) IgG Alexa Fluor 594 (Abcam; ab150088) and 1:100 diluted goat anti-chicken (GAC) IgG Alexa Fluor 633 (A-21103) secondary antibodies. For nuclear staining, cells were treated with 1:15,000X DAPI solution and incubated at RT for $3 \mathrm{~min}$. They were mounted with Vectashield mounting medium (Vector Laboratories, Burlingame, CA, USA). During neuronal differentiation, cell images for each specific time point were obtained under a fluorescent microscope (Zeiss LSM780 Confocal Microscope).

BrdU cell proliferation assay. hMSCs were seeded as triplicates in 96-well plates $\left(3 \times 10^{3}\right.$ cells $\left./ \mathrm{cm}^{2}\right)$ in $100 \mu \mathrm{l}$ of medium. After $24 \mathrm{~h}$, hMSCs were induced towards neural differentiation. Then, $4 \mathrm{~h}$ and $24 \mathrm{~h}$ after the induction, BrdU assay (Cell proliferation ELISA, BrdU, ROCHE, Branchburg, NJ, USA) was performed according to the manufacturer's instructions. Absorbance was measured at 370 $\mathrm{nm}$ using an ELISA reader (SpectraMax).

Cell death analysis. Active caspase- 3 is a downstream marker of apoptosis. Neuronal-induced hMSCs were evaluated for caspase-3 activation to analyse cell death during neuronal differentiation in culture. Accordingly, hMSCs were seeded into $35 \mathrm{~mm}$ petri dishes $\left(3,000\right.$ cells $\left./ \mathrm{cm}^{2}\right)$. After $24 \mathrm{~h}$, the culture medium was replaced with induction medium. At days 2, 6, and 12 cells were collected and caspase- 3 activity (caspase- 3 assay kit, BD Pharmingen, San Jose, CA, USA) was measured according to the manufacturer's instructions. In positive control cells, apoptosis was induced by treatment with camptothecin (Sigma). Caspase-3 activity was inhibited by Z-DEVD-FMK (Sigma) treatment.

Nuclear diameter measurements. The diameter changes in nuclei of both neuronal induced or uninduced hMSCs at day 12 were calculated by Zen Blue Software (Zeiss Inverted Microscope with Hoffman Modulation). A region of interest (ROI) on 10 different images was determined for each time point. A total of 200 cells/group were investigated on DAPI stained cell nuclei for determination of changes in diameter via Violin plot. Welch's $t$-test was used for comparisons.

Reverse transcriptase PCR (RT-PCR). RNA samples of hMSCs were extracted by RNeasy kit (Qiagen, Venlo, the Netherlands). 0.5 $\mu \mathrm{g}$ of total RNA was reverse transcribed to obtain cDNA by Quantitect Reverse Transcription kit (Qiagen). A cDNA library was obtained after 35 cycles of amplification (PCR core kit, Qiagen). Primer pairs (Forward; $\mathrm{FW}$ and Reverse; Rv) used in the experiments were as follows: Integrin $\alpha 5$ (Fw: 5'-AGCCTGTGGA GTACAAGTCC-3' and Rv: 5'-AAGTAGGAGGCC ATCTGTTC3') generating $584 \mathrm{bp}$ fragment; Integrin $\beta 1$ (Fw: 5'AGCAGGGCCA AATTGTGGGT-3' and Rv: 5'-CCACCAAGT TTCCCATCTCC-3') generating 756 bp fragment. A human GAPDH primer pair (Fw: 5'-GTCAGTGGTGGACCTGACCT-3', Rv: 5'-TGCTGTAGCCAAATTCGTTG-3') generating a 245 bp fragment was used as a positive control.
Western blotting. hMSCs were seeded into $1.0-1.5 \times 10^{5}$ cells/well into glass bottom 6-well plates and incubated at $37^{\circ} \mathrm{C}$ in $5 \% \mathrm{CO}_{2}$ for $24 \mathrm{~h}$. Protein lysates were obtained using RIPA lysis buffer (Thermo Fischer Scientific, Waltham, MA, USA; \#89900). Equal amounts of protein samples were run on SDS-PAGE; subsequently gels were transferred by using the iBlot-2 Dry Blotting (Thermo Fisher Scientific) system. After the blocking step, the membrane was probed with primary antibodies: anti-Integrin $\alpha 5 \beta 1$ (Chemicon, Mouse Human $0.25 \mu \mathrm{g} / \mathrm{ml}$, monoclonal) and anti-Actin (Santa Cruz, Rabbit Human $1 \mu \mathrm{g} / \mathrm{ml}$, polyclonal). After labelling with primary antibody, the membrane was washed with Tris Buffered Saline with Tween-20 (TBST) and treated with Horse radish peroxidase (HRP)labeled goat-anti mouse or goat anti rabbit secondary antibody (GAM-HRP, GAR-HRP, Chemicon) for $1 \mathrm{~h}$ at RT. After applying the ECL substrate (Bio-Rad, Hercules, CA, USA), the ChemiDoc MP Imaging System (Bio-Rad) was used and protein bands were chemiluminescently detected.

Statistics. Statistical analsyses were performed by unpaired Student's $t$-test for comparisons between 2 groups. One way ANOVA and a post-hoc test (Bonferroni) were applied when comparing three or more groups. Differences were considered statistically significant at $p<0.001(*)$ and $p<0.0001(* *)$. Data are shown as mean \pm standard error $(\mathrm{SE})$.

\section{Results}

Human mesenchymal stem cells (hMSCs) differentiated into viable neurons in vitro. As for neuronal induction, a bone marrow derived hMSC cell line (UE7T-13 cells, no RBRCRCB2161; RIKEN) was used in experimental settings as previously described (43). Firstly, hMSC cells were immunophenotyped and more than $99 \%$ of the cells were positive for the mesenchymal stem cell markers CD44, CD73, CD90 and CD105, while negative for hematopoietic lineage markers CD34 and CD45 (Figure 1A). Afterwards, hMSCs were iduced towards neuronal differantiation in the presence of certain cytokine combinations for 12 days and showed neurite outgrowths in culture (Figure 1B). Neuronal induced hMSCs were then examined for neuron spesific enolase (NSE) and neurofilament (NF) neuronal protein expression. Both neuronal proteins were expressed in differentiated hMSCs (Figure 1C). The data were correlated with our previous findings in hMd-Neurons (43). To investigate apoptosis, caspase-3 activity was measured in neuronal induced cells, as caspase- 3 is involved in the downstream signaling of the apoptotic cascade. Assay results showed that induced hMSCs did not show any increase in caspase-3 activity. Conversely, camptotechin (CAM)- treated positive control cells displayed significant caspase-3 activation when compared to uninduced or induced hMSCs or apoptosis inhibited hMSCs $(p<0.0001)$ (Figure 1D). These results indicate that the viability of neuronal induced hMSCs was maintained while the cells underwent neural differentiation and/or maturation. 
A
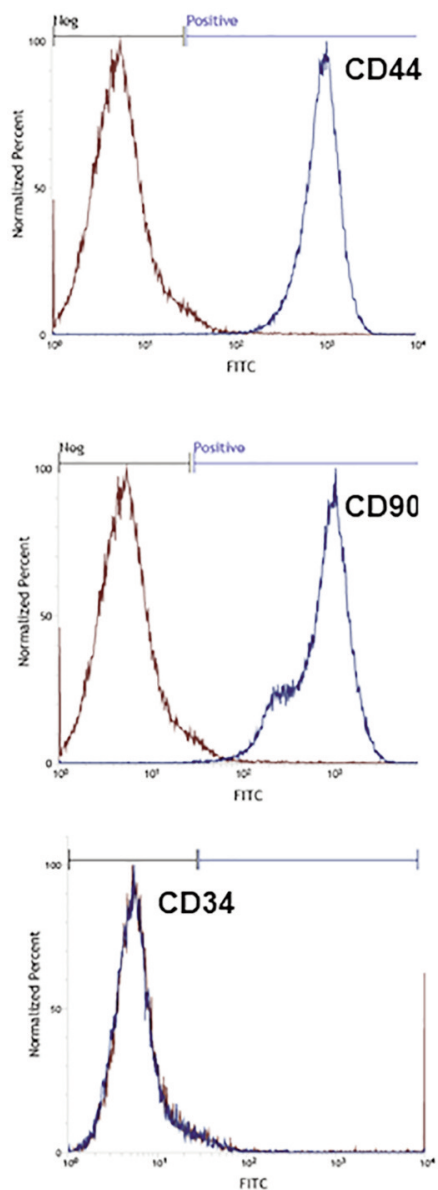

B
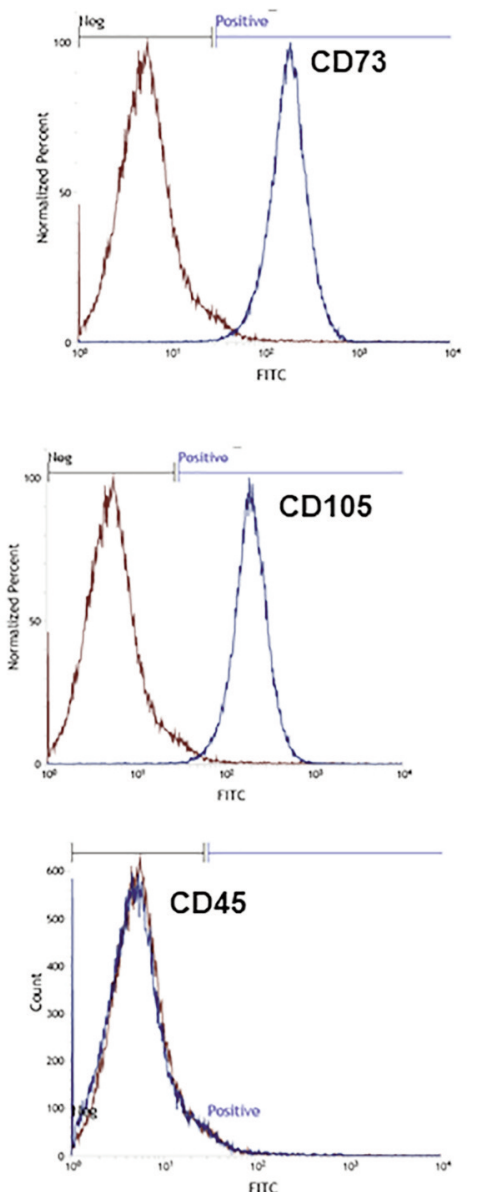

C
hMSCs
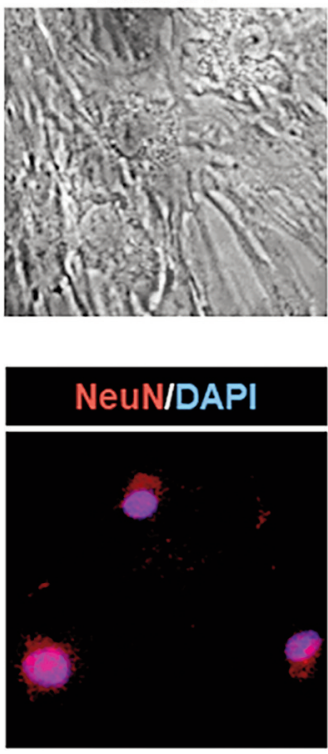

口 hMSCs

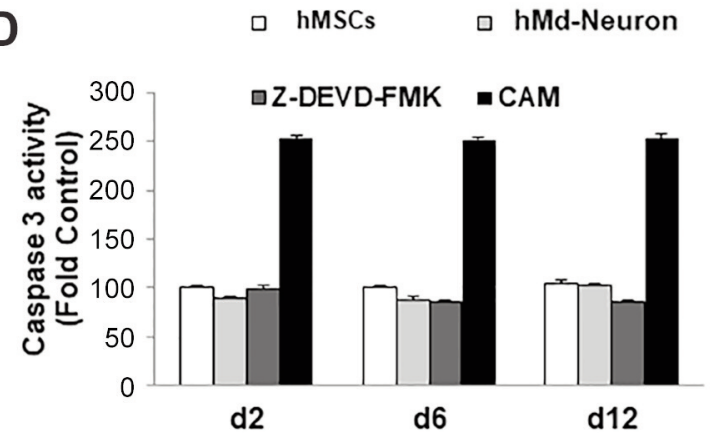

Figure 1. Derivation of neurons from hMSCs (hMd-Neurons). A) hMSC immunophenotyping by flow cytometry shows that cells are positive for MSC markers CD44, CD73, CD90, and CD105 while lacking hematopoietic lineage markers CD34 and CD45. B) Bright field images of hMd-Neurons and uninduced hMSCs (40X). C) Immunoflourescence images of NeuN and Neurofilament (NF) in hMd-Neurons at day 12 (40x). D) Caspase 3 assay for induced, uninduced hMSCs as well as CAM treated (apoptosis inducer; positive control) and Z-DEVD-FMK treated (apoptosis inhibitor; negative control) hMSCs at days 2-12. CAM treated hMSCs show significant caspase 3 activity. Data represent mean $\pm S E ; p<0.0001$.

Neural induction led to cellular reorganization of hMSCs. Considering neuro-developmental processes, newborn neurons from stem cells are expected to loose their highly proliferative ability and reach a post-mitotic phase. Thus, to study conversion of hMSCs into neuronal cells, the proliferation ability of neuronal induced hMSCs within $48 \mathrm{~h}$ was analysed As observed, hMSCs gain neuronal cell morphology by day 1 , stabilize in number by day 2 , then maintain the neuronal cell percentages during the following 12 days in culture. Considering the timing of morphological changes observed in culture BrdU assay was applied 4, 24, and $48 \mathrm{~h}$ after neuronal induction. The assay results confirmed that the proliferation rate was significantly decreased in neuronal induced hMSCs after $48 \mathrm{~h}(p<0.001)$
(Figure 2A). In addition to that, the cell bodies and nuclei of the neural induced hMSCs were $50 \%$ reduced $(p<0.0001$ compared to control) (Figure 2B and C).

Integrin $\alpha 5 \beta 1$ localization differs during neuronal differentiation of hMSCs. Integrin receptor expression was analysed for its contribution to cell motility during the differentiation of hMSCs (44-46). The mRNA and protein levels of integrin $\alpha 5 \beta 1$ at day 12 of hMSC-neural induction were evaluated. Integrin $\alpha 5$ subunit transcripts (mRNAs) were significantly increased at day 12 of hMd-Neurons, as compared to the uninduced hMSCs. Conversely, integrin $\beta 1$ levels were similar in both hMSCs and hMd-Neurons at day 12 of the neuronal induction (Figure 3A). Endogenous 
A

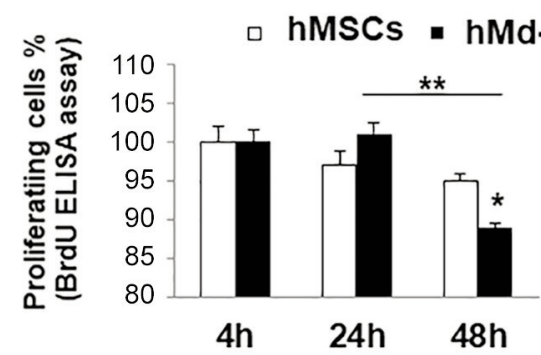

B

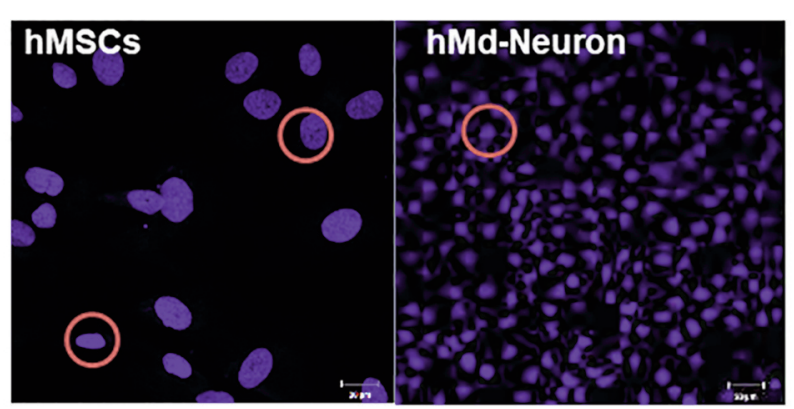

C

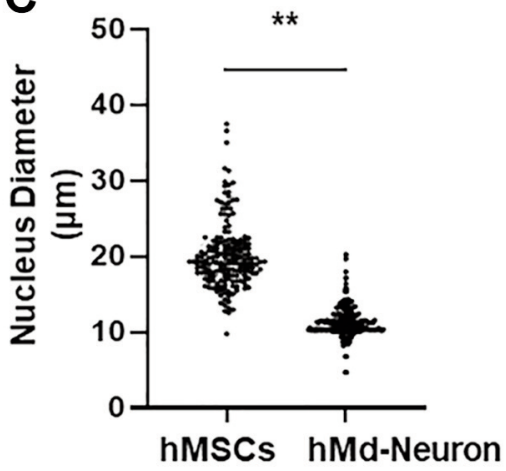

Figure 2. Cellular rearrangements during hMSC differentiation into neurons. A) BrdU assay showing that hMSC proliferation decreases by neuronal differentiation within $48 \mathrm{~h}$ after neuronal induction. B) Florescent images of DAPI staining in uninduced hMSCs and hMd-Neurons (40X). Data represents mean $\pm S E . C)$ Violin plot indicating changes in nucleus diameter in hMSCs when reaching day 12 of neuronal differentiation. Each dot represents a single cell. Plot width is proportional to cell frequency at a given diameter. $p<0.001$ and $p<0.0001$ using Welch's $t$-test.

expression of integrin $\alpha 5 \beta 1$ was significantly increased in hMd-Neurons by day 6 of neuronal induction and variation in $\alpha 5 \beta 1$ integrin expression was detected during neuronal differentiation (Figure 3B). The change in expression led us to further examine the localization of integrin $\alpha 5 \beta 1$ during differentiation into hMd-Neurons. At the early stages of differentiation, by day 2 , integrin $\alpha 5 \beta 1$ was localized at both the membrane and cytoplasm (Figure 3C). At day 6, integrin $\alpha 5 \beta 1$ was mostly localized at the membrane, seen as a bright circular staining (Figure 3D), and by day 12, it was internalized into the cytoplasm (Figure 3E). Quantification analysis also indicated that integrin $\alpha 5 \beta 1$ was localized at the cell surface of hMd-Neurons at day 6, compared to earlier (day 2) or later (day 12) phases of differentiation (Figure 3F). Additionally, at day $12, \alpha 5 \beta 1$ was mostly internalized in hMd-Neurons as shown by the cytoplasmic specific staining and image analysis (Figure 3E and F).

\section{Discussion}

This study showed that neuronal induction leads to cellular reorganization of hMSCs. This dynamic change of hMSCs involves regulation of proliferation in response to differentiation inducers. One of the integrin family receptors, integrin $\alpha 5 \beta 1$, increased at day 6 compared to day 2 of cytokine-mediated neural differentiation and levels were maintained at day 12 . To understand the role of this integrin, we stained hMd-Neurons to study the localization of integrin $\alpha 5 \beta 1$ and our results showed that it was localized mainly at the cell membrane at day 6 , and relocalized in the cytosol at day 12 . According to these findings, intermediate stages of differentiation (in this case, around day 6 ) is possibly a critical time point for differentiation/maturation. Cells require integrins on their membrane to transmit extracellular signals in order to enhance their interaction with surrounding cells and the extracellular matrix (ECM), and to maintain survival, growth and/or differentiation. Considering neural development in adult neurogenesis, more neurite extensions give rise to more connections and survival, which is most likely through a process related to integrins. The findings of this study also suggest that integrin kinetics lead to more neurite extensions around day 6 of hMd-neurons' differentiation. Additionally, previous reports have shown that integrin $\alpha 5 \beta 1$ binding to fibronectin (Fn) guides ECM assembly, and the lack of this interaction may result in lethality during vertebrate development. Therefore, integrin $\alpha 5 \beta 1$ and Fn engagement has been a promising area to focus on in order to optimize succesfull differentiation protocols; the crucial role of integrin $\alpha 5 \beta 1$ binding to Fn was also reported for mesodermal 

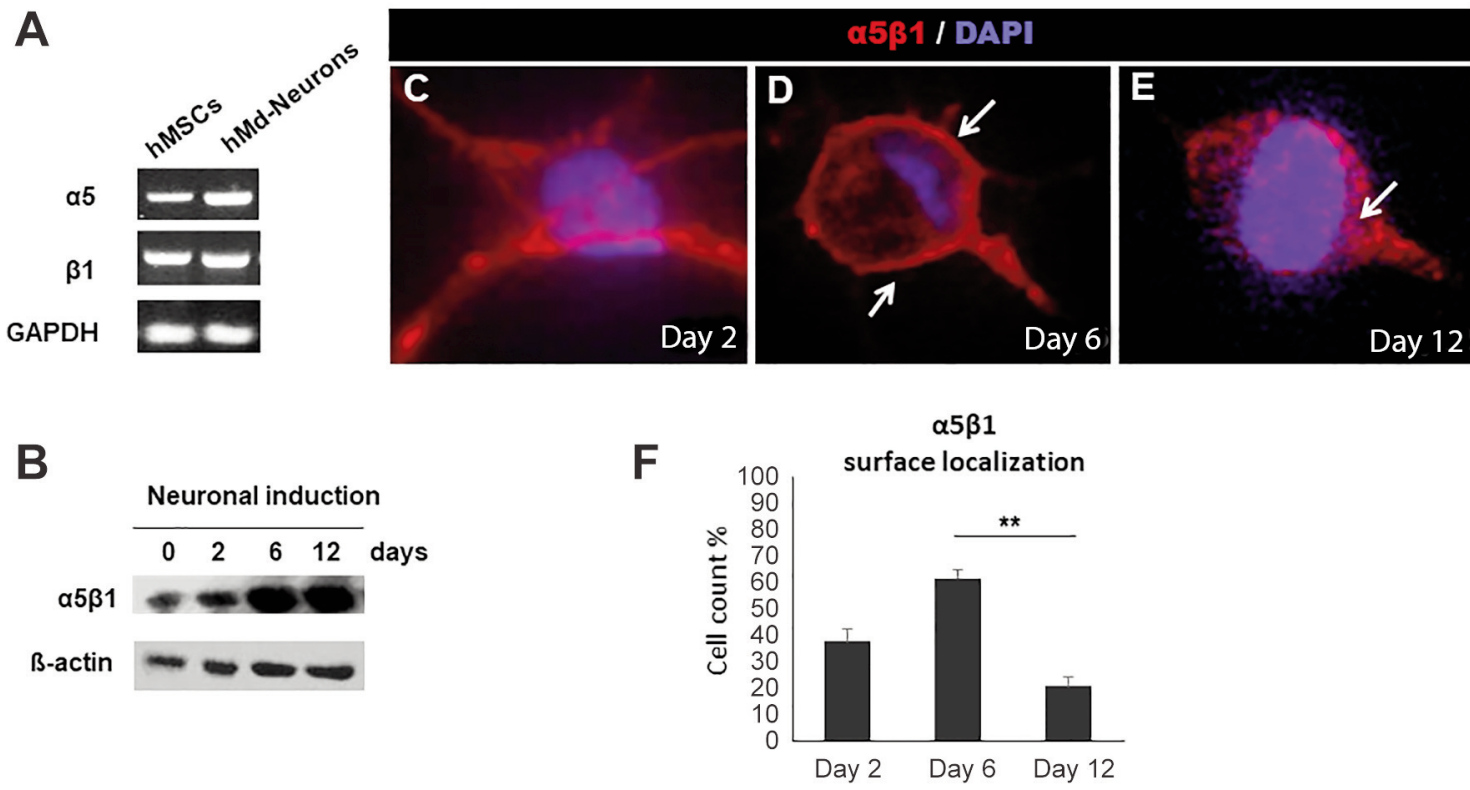

Figure 3. Integrin $\alpha 5 \beta 1$ expression dynamics of hMd-Neurons. A) Transcripts of $\alpha 5$ and $\beta 1$ in hMSCs and hMd-Neurons at day 12. B) Endogenous protein expression levels of integrin $\alpha 5 \beta 1$ and $C$-E) fluorescent images of integrin $\alpha 5 \beta 1$ localization during neuronal differentiation of hMSCs. $F$ ) Plots indicate percentage of integrin $\alpha 5 \beta 1$ cell surface localization among stained cells at days 2, 6, and 12 of differentiation. One hundred cells from three different regions were counted and data represent mean $\pm S E, p<0.001$.

differentiation of hMSCs. Each induction protocol has its own molecular signature and determination of specific cell surface molecules and their ECM partners may alter the induction protocol. This may then guide maturation or spesification of differentiating cells. Our findings show that integrin $\alpha 5 \beta 1$ can guide transdifferentiation of hMSCs into neurons. Considering its expression profile and surface localization during neuronal differentiation, integrin $\alpha 5 \beta 1$ is most likely involved in rearrangement of hMSCs for neuronal maturation around day 6. Although our findings and observations with hMd-Neuron suggests day 6 as a specific time point for neuronal differentiation, this may vary depending on the hMSC donor. Taken together, Fn binding moieties of integrin $\alpha 5 \beta 1$ could be possible substrates guiding the fate of neuronal differentiation/maturation of hMSCs, since $\alpha 5 \beta 1$ is a fibronectin receptor and transmits signals from the extracellular environment to inside the cell. In the future, determination of the integrin dimers' involvement in hMd-Neuron differentiation may provide a well defined structure of neuronal maturation or specification. This can ultimately lead to building optimized tissue scaffolds for neuronal tissue engineering. In terms of the cytoskeletal mechanisms related to integrin dynamics, modulation of the actin cytoskeleton and the study of the signaling pathways involved, will increase understanding of the mechanism of neuronal differentiation from mesodermal lineage to neuroectodermal cells and the essential molecules involved in this process.
Taken together, this study revealed the importance of integrin $\alpha 5 \beta 1$ in the establishment of hMSC niche during in vitro differentiation of hMSCs into hMd-Neurons. The molecular mechanisms of this interaction can be further investigated considering integrin linked cellular processes required for hMdNeuron maturation or specification. Accordingly, focusing on the involvement of different integrin heterodimers during hMdNeuron differentiation may contribute more to the integrin dependent transdifferentiation of hMSCs.

\section{Conflicts of Interest}

The Authors declare no conflicts of interest in relation to this study.

\section{Authors' Contributions}

N.K.: Conception and design, financial support, provision of study material, assembly of data, data analysis and interpretation, manuscript writing, final approval of the manuscript. U.K.: Assembly of data, data analysis and interpretation, manuscript writing, final approval of the manuscript.

\section{Acknowledgements}

This study was supported by İstanbul Medipol University, Scientific Research Projects Committee (BAP) with project number 2019-14 (N.K.). The Authors would like to thank Birnur Sinem Karaoğlan for the literature review and help with manuscript formatting. 


\section{References}

1 Kimbrel EA and Lanza R: Next-generation stem cells - ushering in a new era of cell-based therapies. Nat Rev Drug Discov 19(7): 463-479, 2020. PMID: 32612263. DOI: 10.1038/s41573-0200064-X

2 Yin JQ, Zhu J and Ankrum JA: Manufacturing of primed mesenchymal stromal cells for therapy. Nat Biomed Eng 3(2): 90104, 2019. PMID: 30944433. DOI: 10.1038/s41551-018-0325-8

3 Kadereit S, Deeds LS, Haynesworth SE, Koc ON, Kozik MM, Szekely E, Daum-Woods K, Goetchius GW, Fu P, Welniak LA, Murphy WJ and Laughlin MJ: Expansion of LTC-ICs and maintenance of p21 and BCL-2 expression in cord blood CD34(+)/CD38(-) early progenitors cultured over human MSCs as a feeder layer. Stem Cells 20(6): 573-582, 2002. PMID: 12456965. DOI: 10.1634/stemcells.20-6-573

4 Nancarrow-Lei R, Mafi P, Mafi R and Khan W: A systemic review of adult mesenchymal stem cell sources and their multilineage differentiation potential relevant to musculoskeletal tissue repair and regeneration. Curr Stem Cell Res Ther 12(8): 601-610, 2017. PMID: 28595566. DOI: 10.2174/ $1574888 X 12666170608124303$

5 Friedenstein AJ, Chailakhjan RK and Lalykina KS: The development of fibroblast colonies in monolayer cultures of guineapig bone marrow and spleen cells. Cell Tissue Kinet 3(4): 393-403, 1970. PMID: 5523063. DOI: 10.1111/j.1365-2184.1970.tb00347.x

6 Friedenstein AJ, Gorskaja JF and Kulagina NN: Fibroblast precursors in normal and irradiated mouse hematopoietic organs. Exp Hematol 4(5): 267-274, 1976. PMID: 976387.

7 Majka M, Sułkowski M, Badyra B and Musiałek P: Concise review: Mesenchymal stem cells in cardiovascular regeneration: Emerging research directions and clinical applications. Stem Cells Transl Med 6(10): 1859-1867, 2017. PMID: 28836732. DOI: $10.1002 / \mathrm{sctm} .16-0484$

8 Kim JH, Jo CH, Kim HR and Hwang YI: Comparison of immunological characteristics of mesenchymal stem cells from the periodontal ligament, umbilical cord and adipose tissue Stem Cells Int 2018: 8429042, 2018. PMID: 29760736. DOI: $10.1155 / 2018 / 8429042$

9 Guerrouahen BS, Sidahmed H, Al Sulaiti A, Al Khulaifi M and Cugno C: Enhancing mesenchymal stromal cell immunomodulation for treating conditions influenced by the immune system. Stem Cells Int 2019: 7219297, 2019. PMID: 31467564. DOI: 10.1155/2019/7219297

10 Gorabi AM, Kiaie N, Barreto GE, Read MI, Tafti HA and Sahebkar A: The therapeutic potential of mesenchymal stem cell-derived exosomes in treatment of neurodegenerative diseases. Mol Neurobiol 56(12): 8157-8167, 2019. PMID: 31197655. DOI: 10.1007/s12035-019-01663-0

11 Bhat S, Viswanathan P, Chandanala S, Prasanna SJ and Seetharam RN: Expansion and characterization of bone marrow derived human mesenchymal stromal cells in serum-free conditions. Sci Rep 11(1): 3403, 2021. PMID: 33564114. DOI: 10.1038/s41598-021-83088-1

12 Petrenko Y, Vackova I, Kekulova K, Chudickova M, Koci Z, Turnovcova K, Kupcova Skalnikova H, Vodicka P and Kubinova $\mathrm{S}$ : A comparative analysis of multipotent mesenchymal stromal cells derived from different sources, with a focus on neuroregenerative potential. Sci Rep 10(1): 4290, 2020. PMID: 32152403. DOI: $10.1038 / \mathrm{s} 41598-020-61167-\mathrm{z}$
13 Ciuffreda MC, Malpasso G, Musarò P, Turco V and Gnecchi M: Protocols for in vitro differentiation of human mesenchymal stem cells into osteogenic, chondrogenic and adipogenic lineages. Methods Mol Biol 1416: 149-158, 2016. PMID: 27236670. DOI: 10.1007/978-1-4939-3584-0_8

14 Sanchez-Ramos J, Song S, Cardozo-Pelaez F, Hazzi C, Stedeford T, Willing A, Freeman TB, Saporta S, Janssen W, Patel N, Cooper DR and Sanberg PR: Adult bone marrow stromal cells differentiate into neural cells in vitro. Exp Neurol 164(2): 247-256, 2000. PMID: 10915564. DOI: 10.1006/ exnr.2000.7389

15 Woodbury D, Schwarz EJ, Prockop DJ and Black IB: Adult rat and human bone marrow stromal cells differentiate into neurons. J Neurosci Res 61(4): 364-370, 2000. PMID: 10931522. DOI: 10.1002/1097-4547(20000815)61:4<364::AID-JNR2>3.0.CO;2-C

16 Zhao LR, Duan WM, Reyes M, Keene CD, Verfaillie CM and Low WC: Human bone marrow stem cells exhibit neural phenotypes and ameliorate neurological deficits after grafting into the ischemic brain of rats. Exp Neurol 174(1): 11-20, 2002. PMID: 11869029. DOI: 10.1006/exnr.2001.7853

17 Hou L, Cao H, Wang D, Wei G, Bai C, Zhang Y and Pei X: Induction of umbilical cord blood mesenchymal stem cells into neuron-like cells in vitro. Int J Hematol 78(3): 256-261, 2003. PMID: 14604286. DOI: 10.1007/BF02983804

18 Fan CG, Tang FW, Zhang QJ, Lu SH, Liu HY, Zhao ZM, Liu B, Han ZB and Han ZC: Characterization and neural differentiation of fetal lung mesenchymal stem cells. Cell Transplant 14(5): 311-321, 2005. PMID: 16052912. DOI: 10.3727/ 000000005783983070

19 Tondreau T, Meuleman N, Delforge A, Dejeneffe M, Leroy R, Massy M, Mortier C, Bron D and Lagneaux L: Mesenchymal stem cells derived from CD133-positive cells in mobilized peripheral blood and cord blood: proliferation, Oct4 expression and plasticity. Stem Cells 23(8): 1105-1112, 2005. PMID: 15955825. DOI: $10.1634 /$ stemcells.2004-0330

20 Deng J, Petersen BE, Steindler DA, Jorgensen ML and Laywell ED: Mesenchymal stem cells spontaneously express neural proteins in culture and are neurogenic after transplantation. Stem Cells 24(4): 1054-1064, 2006. PMID: 16322639. DOI: 10.1634/stemcells.2005-0370

21 Wenisch S, Trinkaus K, Hild A, Hose D, Heiss C, Alt V, Klisch C, Meissl H and Schnettler R: Immunochemical, ultrastructural and electrophysiological investigations of bone-derived stem cells in the course of neuronal differentiation. Bone 38(6): 911921, 2006. PMID: 16418015. DOI: 10.1016/j.bone.2005.10.021

22 Krampera M, Marconi S, Pasini A, Galiè M, Rigotti G, Mosna F, Tinelli M, Lovato L, Anghileri E, Andreini A, Pizzolo G, Sbarbati A and Bonetti B: Induction of neural-like differentiation in human mesenchymal stem cells derived from bone marrow, fat, spleen and thymus. Bone 40(2): 382-390, 2007. PMID: 17049329. DOI: $10.1016 /$ j.bone.2006.09.006

23 Venkatesh K and Sen D: Mesenchymal stem cells as a source of dopaminergic neurons: A potential cell based therapy for Parkinson's disease. Curr Stem Cell Res Ther 12(4): 326-347, 2017. PMID: 27842480. DOI: 10.2174/1574888X12666161114122059

24 Singh M, Vaishnav PK, Dinda AK and Mohanty S: Evaluation of priming efficiency of forskolin in tissue-specific human mesenchymal stem cells into dopaminergic neurons: An in vitro comparative study. Cells 9(9): 2058, 2020. PMID: 32917012. DOI: $10.3390 /$ cells 9092058 
25 Khan AA, Huat TJ, Al Mutery A, El-Serafi AT, Kacem HH, Abdallah SH, Reza MF, Abdullah JM and Jaafar H: Significant transcriptomic changes are associated with differentiation of bone marrow-derived mesenchymal stem cells into neural progenitor-like cells in the presence of bFGF and EGF. Cell Biosci 10: 126, 2020. PMID: 33133516. DOI: 10.1186/s13578020-00487-z

26 Okolicsanyi RK, Griffiths LR and Haupt LM: Mesenchymal stem cells, neural lineage potential, heparan sulfate proteoglycans and the matrix. Dev Biol 388(1): 1-10, 2014. PMID: 24509075. DOI: 10.1016/j.ydbio.2014.01.024

27 Gronthos S, Simmons PJ, Graves SE and Robey PG: Integrinmediated interactions between human bone marrow stromal precursor cells and the extracellular matrix. Bone 28(2): 174-181, 2001. PMID: 11182375. DOI: 10.1016/s8756-3282(00)00424-5

28 Vadalà G, Ambrosio L, Russo F, Papalia R and Denaro V: Interaction between mesenchymal stem cells and intervertebral disc microenvironment: from cell therapy to tissue engineering. Stem Cells Int 2019: 2376172, 2019. PMID: 32587618. DOI: $10.1155 / 2019 / 2376172$

29 Xu L, Liu Y, Sun Y, Wang B, Xiong Y, Lin W, Wei Q, Wang H, $\mathrm{He}$ W, Wang B and Li G: Tissue source determines the differentiation potentials of mesenchymal stem cells: a comparative study of human mesenchymal stem cells from bone marrow and adipose tissue. Stem Cell Res Ther 8(1): 275, 2017. PMID: 29208029. DOI: 10.1186/s13287-017-0716-x

30 Liang X, Garcia BL, Visai L, Prabhakaran S, Meenan NA, Potts JR, Humphries MJ and Höök M: Allosteric regulation of fibronectin/ $\alpha 5 \beta 1$ interaction by fibronectin-binding MSCRAMMs. PLoS One 11(7): e0159118, 2016. PMID: 27434228. DOI: 10.1371/journal.pone.0159118

31 Zhou X, Zhai Y, Liu C, Yang G, Guo J, Li G, Sun C, Qi X, Li X and Guan F: Sialidase NEU1 suppresses progression of human bladder cancer cells by inhibiting fibronectin-integrin $\alpha 5 \beta 1$ interaction and Akt signaling pathway. Cell Commun Signal 18(1): 44, 2020. PMID: 32164705. DOI: 10.1186/s12964-019-0500-x

32 Mamidi A, Prawiro C, Seymour PA, de Lichtenberg KH, Jackson A, Serup P and Semb H: Mechanosignalling via integrins directs fate decisions of pancreatic progenitors. Nature 564(7734): 114118, 2018. PMID: 30487608. DOI: 10.1038/s41586-018-0762-2

33 Toniatti C, Bujard H, Cortese R and Ciliberto G: Gene therapy progress and prospects: transcription regulatory systems. Gene Ther 11(8): 649-657, 2004. PMID: 14985790. DOI: 10.1038/ sj.gt. 3302251

$34 \mathrm{Li} \mathrm{B}$, Moshfegh $\mathrm{C}$, Lin $\mathrm{Z}$, Albuschies $\mathrm{J}$ and Vogel $\mathrm{V}$ : Mesenchymal stem cells exploit extracellular matrix as mechanotransducer. Sci Rep 3: 2425, 2013. PMID: 23939587. DOI: $10.1038 /$ srep02425

35 Shuaib A, Motan D, Bhattacharya P, McNabb A, Skerry TM and Lacroix D: Heterogeneity in the mechanical properties of integrins determines mechanotransduction dynamics in bone osteoblasts. Sci Rep 9(1): 13113, 2019. PMID: 31511609. DOI: 10.1038/s41598-019-47958-z

36 Matziolis D, Tuischer J, Matziolis G, Kasper G, Duda G and Perka C: Osteogenic predifferentiation of human bone marrowderived stem cells by short-term mechanical stimulation. Open Orthop J 5: 1-6, 2011. PMID: 21270950. DOI: 10.2174/ 1874325001105010001
37 Di Benedetto A, Brunetti G, Posa F, Ballini A, Grassi FR, Colaianni G, Colucci S, Rossi E, Cavalcanti-Adam EA, Lo Muzio L, Grano M and Mori G: Osteogenic differentiation of mesenchymal stem cells from dental bud: Role of integrins and cadherins. Stem Cell Res 15(3): 618-628, 2015. PMID: 26513557. DOI: 10.1016/j.scr.2015.09.011

38 Fraioli R, Dashnyam K, Kim JH, Perez RA, Kim HW, Gil J, Ginebra MP, Manero JM and Mas-Moruno C: Surface guidance of stem cell behavior: Chemically tailored co-presentation of integrin-binding peptides stimulates osteogenic differentiation in vitro and bone formation in vivo. Acta Biomater 43: 269-281, 2016. PMID: 27481289. DOI: 10.1016/j.actbio.2016.07.049

39 Attia M, Santerre JP and Kandel RA: The response of annulus fibrosus cell to fibronectin-coated nanofibrous polyurethaneanionic dihydroxyoligomer scaffolds. Biomaterials 32(2): 450460, 2011. PMID: 20880584. DOI: 10.1016/j.biomaterials. 2010.09.010

40 Girós A, Grgur K, Gossler A and Costell M: $\alpha 5 \beta 1$ integrinmediated adhesion to fibronectin is required for axis elongation and somitogenesis in mice. PLoS One 6(7): e22002, 2011. PMID: 21799763. DOI: 10.1371/journal.pone.0022002

41 Liang D, Wang X, Mittal A, Dhiman S, Hou SY, Degenhardt K and Astrof S: Mesodermal expression of integrin $\alpha 5 \beta 1$ regulates neural crest development and cardiovascular morphogenesis. Dev Biol 395(2): 232-244, 2014. PMID: 25242040. DOI: 10.1016/j.ydbio.2014.09.014

42 Martino MM, Mochizuki M, Rothenfluh DA, Rempel SA, Hubbell JA and Barker TH: Controlling integrin specificity and stem cell differentiation in $2 \mathrm{D}$ and $3 \mathrm{D}$ environments through regulation of fibronectin domain stability. Biomaterials 30(6): 1089-1097, 2009. PMID: 19027948. DOI: 10.1016/ j.biomaterials.2008.10.047

43 Karakaş N, Bay S, Türkel N, Öztunç N, Öncül M, Bilgen H, Shah K, Şahin F and Öztürk G: Neurons from human mesenchymal stem cells display both spontaneous and stimuli responsive activity. PLoS One 15(5): e0228510, 2020. PMID: 32407317. DOI: 10.1371/journal.pone. 0228510

44 Docheva D, Popov C, Mutschler W and Schieker M: Human mesenchymal stem cells in contact with their environment: surface characteristics and the integrin system. J Cell Mol Med 11(1): 21-38, 2007. PMID: 17367499. DOI: 10.1111/j.15824934.2007.00001.x

45 Veevers-Lowe J, Ball SG, Shuttleworth A and Kielty CM: Mesenchymal stem cell migration is regulated by fibronectin through $\alpha 5 \beta 1$-integrin-mediated activation of PDGFR- $\beta$ and potentiation of growth factor signals. J Cell Sci 124(Pt 8): 12881300, 2011. PMID: 21429937. DOI: 10.1242/jcs.076935

46 Dalby M, García A and Salmeron-sanchez M: Receptor control in mesenchymal stem cell engineering. Nature Reviews Materials 3(3), 2020. DOI: 10.1038/natrevmats.2017.91

Received March 31, 2021

Revised April 23, 2021

Accepted April 24, 2021 